\title{
Workshop reports
}

\section{Meetings of directors of World Health Organization collaborating centres in the field of diabetes}

\author{
H. King ${ }^{1}$, S. Leichter ${ }^{2}$ and H. Keen ${ }^{3}$ \\ ${ }^{1}$ Division of Noncommunicable Diseases, World Health Organization, Geneva, Switzerland \\ ${ }^{2}$ Medical College of Hampton Roads, Norfolk, Va, USA \\ ${ }^{3}$ Unit for Metabolic Medicine, United Medical Schools of Guy's and St. Thomas' Hospitals, London, UK
}

The emergence of diabetes as a major and increasing public health problem in both developed and developing countries of the world has resulted in a considerable growth in activities relating to the World Health Organization (WHO) programme for diabetes in recent years.

As compared with the six proposed or designated WHO collaborating centres in the field of diabetes identified in 1984, by 1987 this number had grown to 26. Currently, approximately one-quarter of all WHO collaborating centres associated with the WHO Division of Noncommunicable Diseases (which includes programmes for cancer, cardiovascular diseases, occupational health, oral health, rheumatic diseases and the Integrated Programme for Community Health in Noncommunicable Diseases are designated for diabetes mellitus.

This rather remarkable international development generated a growing feeling that it would be valuable for the centres to meet on suitable occasions. This could foster understanding and promote cooperative activities aimed at supporting the WHO diabetes programme. With this in mind; an informal gathering of heads of existing collaborating centres took place in conjunction with the 12th Congress of the International Diabetes Federation in Madrid, Spain in September 1985.

Thanks to the generous support of the Kentucky Diabetes Foundation, the heads of the WHO collaborating centres in the field of diabetes were able to meet formally for the first time in Lexington, $\mathrm{Ky}$, USA in June 1987. A number of pertinent issues emerged from the meeting.

The history of the WHO activities relating to diabetes were reviewed, including the Expert Committee meetings of 1965 and 1979, and the Study Group meeting of 1985 (the latter two under the chairmanship of Professor H.Keen). These meetings had each resulted in the publication of important technical documents by WHO [1-3] which had proved to represent milestones in the diagnosis, classification and research directions for diabetes.

The 30th anniversary of the association between WHO and the International Diabetes Federation (IDF, which in 1957 became only the second non-governmental organization to develop official relations with WHO) was also acknowledged.

It was recognised that resources for diabetes within the regular budget of WHO were extremely limited. This gave strength to the argument that the network of collaborating centres, with their much greater collective resources, could fulfill a key role in advancing the cause of diabetes internationally. Very lively interest in this concept was expressed by all of those present at the meeting, and much discussion centered the mechanisms, whereby this might be conveniently effected.

The meeting considered the long awaited WHO Action Programme for Diabetes [4] as a natural framework for their activities, and advocated attention to the further development of this concept.
There was also general agreement that a more defined structure for the collaborating centres could assist in their mutual efforts.

The Lexington meeting also convened expert panel sessions which considered the fields of epidemiology, prevention and care, education, clinical research and technology. Each panel produced a series of recommendations and agreed to cooperate together to advance their individual fields. The meeting concluded with the nomination of an informal interim steering group under the chairmanship of Dr. D. Etzwiler, and with warm expressions of gratitude to Dr. S. Leichter, his collcagues and assistants, and the Kentucky Diabetes Foundation for making this historic meeting such a success.

Coinciding with the 13th Congress of the International Diabetes Federation in Sydney, Australia in November 1988, those heads of WHO collaborating centres in the field of diabetes who werc attending the congress took the opportunity to meet again on an informal basis to discuss developments which had taken place since the meeting in Lexington. Under the chairmanship of Dr. Etzwiler, the meeting was honoured and greatly assisted by the participation of two senior representatives of WHO, Dr. Hu Ching-Li, Assistant Director-General and Dr. E. Chigan, Director of the Division of Noncommunicable Diseases.

Dr. Hu gave the meeting the benefit of his considerable experience and insight into the mechanisms by which WHO could interact with its collaborating centres. He also explained that at present, diabetes represented only a component of a single programme within the Division of Noncommunicable Diseases. Although the growing worldwide importance of diabetes was fully recognised by WHO, a number of practical and financial constraints, as well as the competing needs of other disease-oriented programmes, made it very difficult for WHO to extend greater resources to diabetes activities at the present time. The goal of greater permanent staff support for diabetes within the Division of Noncommunicable Diseases had been accepted long ago. The heads of WHO collaborating centres in the field of diabetes, as well as the regional representatives of the IDF, had an important role to play in bringing the diabetes situation to the attention of their representatives at the world Health Assembly.

Dr. H. King, the Medical Officer for diabetes at WHO Headquarters, reviewed some of the recent and future activities of the WHO diabetes programme. These included the three successful seminars on the epidemiology and public health aspects of diabetes held in Cambridge, United Kingdom, the development of a technical manual for diabetes surveys publication of statistical information on diabetes worldwide $[5,6]$ and proposals to develop guidelines for the formulation of diabetes programmes at a national level and to convene another Study Group on diabetes.

The continuing success of the WHO Multinational Study of Vascular Disease in Diabetics [7] was acknowledged. The rapid growth in 
standardised registers of childhood diabetes in recent years was reviewed by Dr. R. LaPorte, and a consensus emerged that the formalisation of this initiative as a WHO Multinational Study of Childhood Diabetes would be highly desirable. Professor Alberti pointed to the very useful contribution of activities related to the WHO Integrated Programme for Community Health in Noncommunicable Diseases (Interhealth) to public health efforts for diabetes, notably in Finland, Mauritius and Tanzania.

The meeting concluded with the sentiment that communication would provide the essence of continuing collaboration. This could take the form of annual reports from collaborating centres, a regular newsletter of collaborating centre activities, and further utilisation of the various electronic mail systems.

A strong desire was expressed to convene another meeting of WHO collaborating centres in the field of diabetes to coincide with the 14th Congress of the International Diabetes Federation in Washington, D. C., USA in 1991.

\section{References}

1. WHO Technical Report Series (1965) No.310 (Diabetes mellitus: report of a WHO expert committee). World Health Organization, Geneva

2. WHO Technical Report Series (1980) No.646 (WHO expert committee on diabetes mellitus: second report). World Health Organization, Geneva

3. WHO Technical Report Series (1985) No.727 (Diabetes mellitus: report of a WHO study group). World Health Organization, Geneva

4. Outlinc summary of programme for diabetes of the WHO/IDF Executive Committee (1985) IDF Bull 30: 17-19

5. Rewers M, LaPorte RE, King H, Tuomilehto J (1988) Trends in the prevalence and incidence of diabetes, I. Insulin-dependent diabetes mellitus in childhood. World Health Stat Q 41: 179-189

6. King H, Zimmet $P(1988)$ Trends in the prevalence and incidence of diabetes, II. Non-insulin-dependent diabetes mellitus. World Health Stat Q 41: 190-196

7. The World Health Organization Multinational Study of Vascular Disease in Diabetics (1985) Prevalence of small vessel and large vessel disease in diabetic patients from 14 centres. Diabetologia 28 [Suppl]: 615-640

Dr. H. King

Division of Noncommunicable Diseases/OND

World Health Organization

$\mathrm{CH}-1211$ Geneva 27

Switzerland

\section{Annex. WHO collaborating centres in the field of diabetes as of December 1988}

\section{Australia}

WHO Collaborating Centre for the Epidemiology of Diabetes Mellitus. Director: Professor P.Zimmet, The Royal Southern Memorial Hospital, P. O. Box 185, Caulfield South 3162, Victoria.

\section{Bangladesh}

WHO Collaborating Centre for Research and Training for Prevention and Control of Diabetes Mellitus. Director: Dr. H.Mahtab, Bangladesh Institute of Research and Rehabilitation in Diabetes, Endocrine \& Metabolic Disorders (BIRDEM), Shahbag Avenue, Dhaka 2.

\section{Belgium}

WHO Collaborating Centre for the Development of the Biology of Endocrine Pancreas. Director: Professor J.J. Hoet, Laboratory of CelIular Biology, Faculty of Medicine, Catholic University of Louvain, Brussels.
Cuba

WHO Collaborating Centre for Integrated Medical Care Services in Diabetes. Director: Professor O. Mateo-de-Acosta, Instituto de Endocrinologia y Enfermedades Metabolicas, Hospital "Cmdte. Fajardo", Havana.

\section{Czechoslovakia}

WHO Collaborating Centre for Development, Management and Evaluation of the National Diabetes Control Programme. Director: Professor J.Rybka, Internal Clinic of the Postgraduate Medical Institute, ILF, Havlickovo nabrezi 600, 762 75, Gottwaldov.

\section{Denmark}

WHO Collaborating Centre for Research and Training on the Pathogenesis of Diabetes Mellitus. Director: Dr. J.Nerup, Steno Memorial Hospital, Niels Steensensvej 2, DK-2820 Gentofte.

Germany, Democratic Republic

WHO Collaborating Centre for Preventive Programmes in Diabetes Health Care. Director: Professor H.Bibergeil, Central Institute for Diabetes, Research and Treatment "Gerhardt Katsch", 2201 Karlsburg - Krs. Greifswald.

\section{Germany, Federal Republic}

WHO Collaborating Centre for Diabetes Treatment and Prevention (Physical Exercise Programs). Director: Professor M.Berger, Medizinische Klinik E, University of Düsseldorf, Moorenstrasse 5, D-4000 Düsseldorf 1 .

\section{Israel}

WHO Collaborating Centre for who Study of Diabetes in Youth. Director: Professor Z.Laron, Institute of Pediatric and Adolescent Endocrinology, Beilinson Medical Center, 49100 Petah Tiqva.

\section{Japan}

WHO Collaborating Centre for Diabetes Treatment and Education. Director: Professor Y.Akazawa, Diabetes Center, Institute of Endocrinology and Metabolic Disease, Kyoto National Hospital, Kyoto 612.

\section{Kuwait}

WHO Collaborating Centre for Diabetes Mellitus. Director: Professor A.R.Al-Yusuf, Department of Medicine, Faculty of Medicine, University of Kuwait, Safat.

\section{Sweden}

WHO Collaborating Centre for Diabetes in Primary Health Care. Director: Dr. U.Rosenqvist, Department of Endocrinology, Karolinska Hospital, Box 60500, S-10401 Stockholm.

\section{Switzerland}

WHO Collaborating Centre for Reference and Research in Diabetes Education. Director: Dr. J.-Ph.Assal, Diabetes Treatment and Teaching Unit. Hôpital Cantonal Universitaire, 1211 Geneva 4.

\section{United Kingdom}

WHO Collaborating Centre for the Study and Control of Long-Term Complications of Diabetes Mellitus. Director: Professor H.Keen, Unit for Metabolic Medicine, Division of Medicine, Guy's Hospital, London SE1 9RT.

WHO Collaborating Centre for Diabetic Morbidity and Mortality. Director: Dr. J.H. Fuller, Diabetes Epidemiology Unit, Department of Community Medicine, University College London and The Middlesex Hospital Medical School, London WC1E 6 EA.

WHO Collaborating Centre for Research and Development in Laboratory Techniques in Diabetes. Director: Professor K.G. M. M. Alberti, Department of Medicine, The University of Newcastle upon Tyne, Floor 4 - Clinical Block, The Medical School, Framlington Place, Newcastle upon Tyne NE2 $4 \mathrm{HH}$. 


\section{United States of America}

WHO Collaborating Centre for the Development of Integrated Primary Care Programme for Community Practice. Director: Dr. A. Ring, Division of Diabetes Control, Center for Preventive Services, Centers for Disease Control, US Public Health Service, Department of Health and Human Services, Atlanta, Ga.30333.

WHO Collaborating Centre for Diabetes Research, Information and Education. Director: Dr. M.I. Harris, National Institute of Arthritis, Diabetes, and Digestive and Kidney Diseases, National Institutes of Health, Bethesda, Md.20205.

WHO Collaborating Centre for Diabetes in Pregnancy. Director: Professor N. Freinkel, Center for Endocrinology, Metabolism and Nutrition, Northwestern University, 303 East Chicago Avenue, Chicago, Ill. 60611.

${ }^{1}$ WHO Collaborating Centre for Primary Care Delivery in Diabetes. Director: Dr. S.B.Leichter, The Kentucky Diabetes Foundation, 120 North Eagle Creek Drive, Lexington, Ky 40509.

WHO Collaborating Centre for Diabetes Education and Training. Director: Dr. D. D. Etzwiler, International Diabetes Center, Park Nicollet Medical Foundation, 5000 West 39th Street, Minneapolis, Minn. 55416.

${ }^{2}$ WHO Collaborating Centre for Behavioural Medicine and Computer Science in Diabetes Research and Management. Director: Dr. R.S. Mazze, Diabetes Research \& Training Center, Albert Einstein College of Medicine \& Montefiore Hospital \& Medical Center, 1300 Morris Park Avenue, Bronx, New York 10461.
WHO Collaborating Centre for Biostatistics in Diabetes. Director: Dr. E.T.Lee, Department of Biostatistics and Epidemiology, The University of Oklahoma Health Sciences Center, Post Office Box 26901, 801 N.E. 13th Street, Oklahoma City, Okla 73190.

WHO Collaborating Centre for Diabetes Registries and Training in the Epidemiology of Diabetes Mellitus. Directors: Dr. R. E. LaPorte and Dr. A.Drash, Department of Epidemiology, Diabetes Research Center, University of Pittsburgh, Suite 502, 3600 Forbes Avenue, Pittsburgh, Penn. 15213.

\section{USSR}

WHO Collaborating Centre for Diabetes Epidemiology and Prevention. Director: Professor Y.A. Pankov, Department of Epidemiology of Diabetes Mellitus, Institute of Experimental Endocrinology and Hormone Chemistry of the Academy of Medical Sciences of the USSR, Dm. Uljanov str. 11, Moscow 117036.

\section{Yugoslavia}

WHO Collaborating Centre for Development of Appropriate Technology in the Control of Diabetes Mellitus. Director: Professor Z.Skrabalo, Institute for Diabetes, Endocrinology and Metabolic Diseases, "Vuk Vrhovac", Dugl dol 4a, 41000 Zagreb.

${ }^{1}$ Presently relocating to the Medical College of Hampton Roads, Norfolk, V. 23501, USA

${ }^{2}$ Presently relocating to the International Diabetes Center, Park Nicollet Medical Foundation, Minneapolis, Minn. 55416, USA 